\title{
Occurrence of Leaf Spot Disease Caused by Alternaria crassa (Sacc.) Rands on Jimson Weed and Potential Additional Host Plants in Algeria
}

\author{
Nabahat Bessadat ${ }^{1,2}$, Bruno Hamon ${ }^{2}$, Nelly Bataillé-Simoneau ${ }^{2}$, Corentin Chateau ${ }^{2}$, Kihal Mabrouk $^{1}$, and \\ Philippe Simoneau (1D) ${ }^{2 *}$ \\ ${ }^{1}$ Applied Microbiology Lab, University Oran1 Ahmed Ben Bella, 31000 Oran, Algeria \\ ${ }^{2} U M R 1345$ IRHS, SFR QUASAV, University Angers, INRA, Agrocampus-Ouest, Angers 49000, France
}

(Received on January 2, 2020; Revised on February 22, 2020; Accepted on February 26, 2020)

A leaf spot pathogen Alternaria sp. was recovered from jimson weed, tomato, parsley, and coriander collected during surveys of blight diseases on Solanaceae and Apiaceae in Algeria. This species produced large conidial body generating long apical beaks that tapered gradually from a wide base to a narrow tip and short conidiophores originating directly from the agar surface. This species exhibited morphological traits similar to that reported for Alternaria crassa. The identification of seven strains from different hosts was confirmed by sequence analyses at the glyceraldehyde-3-phosphate dehydrogenase, RNA polymerase second largest subunit, and translation elongation factor 1-alpha loci. Further the pathogen was evaluated on jimson weed, coriander, parsley, and tomato plants, and this fungus was able to cause necrotic lesions on all inoculated plants. $A$. crassa is reported for the first time as a new species of the $\mathrm{Al}$ gerian mycoflora and as a new potential pathogen for cultivated hosts.

Keywords : Alternaria crassa, leaf spot, morphology, multilocus analysis, pathogenicity

Handling Editor : Jungkwan Lee

*Corresponding author.

Phone) +33-677123755

E-mail)simoneau@univ-angers.fr

ORCID

P. Simoneau

https://orcid.org/0000-0002-3890-9848

(c) This is an Open Access article distributed under the terms of the Creative Commons Attribution Non-Commercial License (http:// creativecommons.org/licenses/by-nc/4.0) which permits unrestricted noncommercial use, distribution, and reproduction in any medium, provided the original work is properly cited.

Articles can be freely viewed online at www.ppjonline.org.
Datura stramonium, known as jimson weed or thorn apple, is spread throughout many temperate and subtropical areas in the world. This wild Solanaceae species is an aggressive colonizer of agricultural fields that competes strongly in summer crops in Algeria (Song, 1987) and many parts of the world (Holm et al., 1997) and is therefore considered as a pest for agricultural reasons. Crop losses due to competition with $D$. stramonium depend on the crop and climatic conditions. For example, at a density of 3-11 plants per $\mathrm{m}^{2}$, yields of directly-seeded tomatoes may be reduced by 26$71 \%$ (Monaco et al., 1981). This weed is also known for its ability to produce toxic alkaloids that cause the death of livestock, hallucinations, and delusions to humans (Chan, 2002; Hoagland and Boyette, 1994). Foliar diseases agents such as Alternaria spp. have been reported on D. stramonium (Ellis and Holliday, 1970; Rands, 1917; Simmons, 2007). In Algeria, Alternaria leaf spot was recorded in north-western regions every year from 2011 to 2017 growing seasons on several Solanaceae species including jimson weed (Bessadat et al., 2019b). Symptoms associated with leaf spot and blight are variable and can differ depending on the host and Alternaria sp. involved. On tomatoes and cultivated Apiaceae, necrotic lesions start as small dark spots, usually on the older leaves, often surrounded by a yellow zone. On D. stramonium, lesions are pale yellow to light brown and commonly have concentric rings with a target-like appearance. At a later stage, when spotting is abundant the entire leaf turns yellow and falls off.

The aim of this study was to consider the occurrence of Alternaria crassa (Sacc.) Rands on cultivated plants and the neighboring wild species $D$. stramonium in the main north-western growing fields of Algeria.

From 2013 to 2018, regular surveys were performed in Solanaceae and Apiaceae fields of three geographic locations of the north-western region viz. Oran, Mostaganem 
and Sidi Bel Abbes. Symptomatic leaves of jimson weed (Fig. 1A), tomato, parsley, and coriander were sampled and taken to a laboratory for further analysis. Leaf pieces of about $0.5 \mathrm{~cm}^{2}$ were cut from the margins of necrotic or chlorotic lesions, surface disinfected with $2 \% \mathrm{NaOCl}$ and rinsed with sterilized distilled water. Samples were then placed on Petri-plates containing potato carrot agar (PCA) medium and incubated at room temperature. After 5 to 14 days of incubation, 339 fungal colonies corresponding to large-spored Alternaria species were collected, purified by monospore culture and sub-culturing techniques. Isolates were further mass cultured in potato sucrose agar (PSA) and stored at $-80^{\circ} \mathrm{C}$ in $30 \%$ glycerol. Based on morphological observations, the vast majority of these isolates could be assigned to species of section Porri. Nine isolates had a different morphology from species already described in Algeria on the same host plants, i.e., A. linariae, A. solani, A. grandis, A. protenta, and A. dauci (Bessadat et al., 2016, 2017, 2019a, 2019b) and were further identified according to Simmons descriptions (2007). They were grown for 7 days in PCA plates, incubated at room temperature with a $12 \mathrm{~h}$ daily photoperiod. Measurements of conidia and conidiophores were performed after 5 to 7 days. Samples were mounted in lactic acid, observed under a microscope (Optika B-190 series, OPTIKA Srl, Via Rigla, Italy) and micro-photographed. Dimensions were based on observing 35 conidia and 20 conidiophores per isolate. Cultural characteristics were studied by inoculating PSA and PCA media with $5 \mathrm{~mm}$ diameter of mycelial plugs. Isolates formed

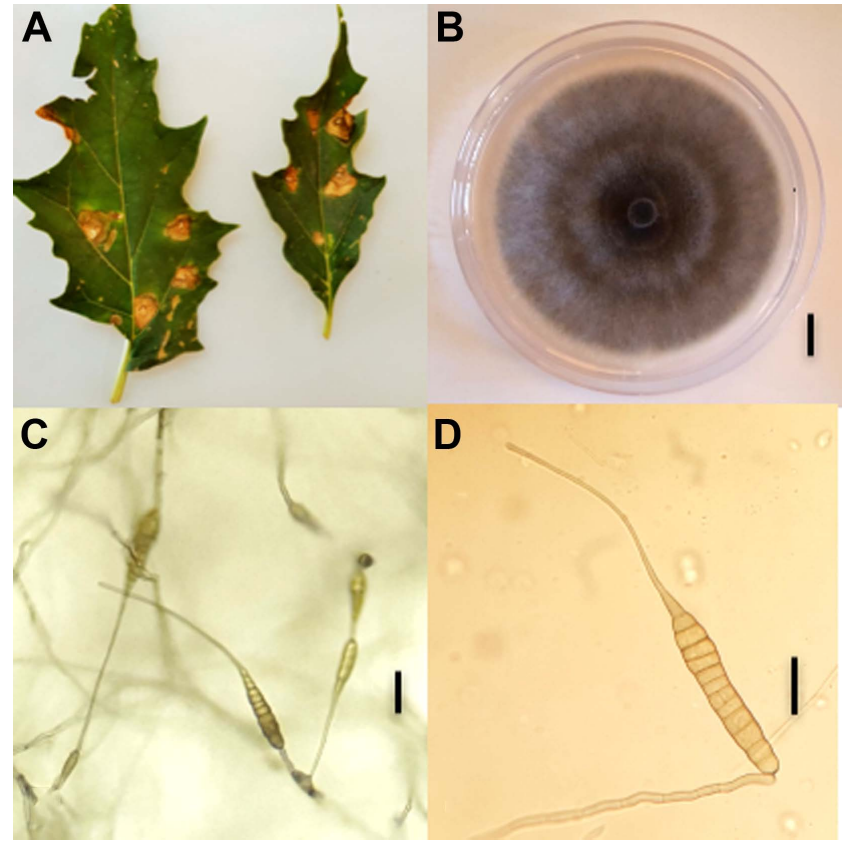

Fig. 1. (A) Leaf spot disease caused by Alternaria crassa on jimson weed. (B) Colony on potato sucrose agar grown for 7 days at $25^{\circ} \mathrm{C}$. Scale bar $=10 \mathrm{~mm}$. (C, D) Conidia and conidiophores produced by NB504 on potato carrot agar grown for 7 days at room temperature. Scale bars $=80 \mu \mathrm{m}(\mathrm{C}), 50 \mu \mathrm{m}(\mathrm{D})$.

greenish-grey cottony colonies with regular white margins (Fig. 1B). Mean colony diameter on PCA medium were $78 \pm 2 \mathrm{~mm}$ and $66 \pm 3 \mathrm{~mm}$ on PSA 7 days after incubation at $25^{\circ} \mathrm{C}$. Isolates produced conidia after 1 week under a

Table 1. Comparison of the conidial morphology of Alternaria crassa with descriptions available in the literature

\begin{tabular}{ccccl}
\hline Body size $(\mu \mathrm{m})$ & Beak size $(\mu \mathrm{m})$ & Transverse septa & Longitudinal septa & Reference \\
\hline $47-168 \times 15-32$ & $100-439$ & $6-12$ & $1-8$ & Present study \\
$55-101.3 \times 13-22.5$ & $195-515 \times 2.5-5.5$ & $5-11$ & $2-8$ & Nishikawa and Nakashima (2013) \\
$122-135 \times 19-26$ & $320-460 \times 6-8$ & $12-16$ & $1-2$ & Simmons (2007) \\
$56-140 \times 16-40$ & $72-308$ & $7-9$ & $1-3$ & Rands (1917) \\
\hline
\end{tabular}

Table 2. Isolates used in this study and their host

\begin{tabular}{lllcccc}
\hline Isolate & Host & Geographic origin & Year & gpd & rpb2 & tef1 \\
\hline NB304 & Jimson weed & Sidi Bel Abbèsse & 2013 & MK513413 & MK513424 & MK513435 \\
NB325 & Jimson weed & Oran & 2014 & MK513414 & MK513425 & MK513436 \\
NB500 & Tomato & Mostaganem & 2017 & MK513415 & MK513426 & MK513437 \\
NB504 & Jimson weed & Mostaganem & 2017 & MK513416 & MK513427 & MK513438 \\
NB512 & Jimson weed & Mostaganem & 2017 & MK513417 & MK513428 & MK513439 \\
NB570 & Coriander & Oran & 2017 & MK513418 & MK513429 & MK513440 \\
NB573 & Parsley & Oran & 2017 & MK513419 & MK513430 & MK513441 \\
NB704 & Jimson weed & Mostaganem & 2018 & NA & NA & NA \\
NB705 & Jimson weed & Mostaganem & 2018 & NA & NA \\
\hline
\end{tabular}


12-h photoperiod at room temperature on PCA medium. Conidia body generated long apical beaks that tapered gradually from a wide base to a narrow tip (Fig. 1C and D). These isolates exhibited a sporulation pattern resembling that of A. crassa (Table 1). Conidia were mostly solitary, pale brown, with a long-ovoid or ellipsoid body, 47-168 $\times$ $15-32 \mu \mathrm{m}$ in size, plus an extremely long beak (up to 430 $\mu \mathrm{m})$. These conidia had up to 6-12 transverse septa and 0-8 longitudinal septa. Conidiophores rising from the agar surface were simple, rarely branched, 22-163 $\times 6-10 \mu \mathrm{m}$ with 1-8 transverse septa. Frequently the tip of beaks became conidiogenous and produced 1-3 additional conidia. Four isolates (NB304, NB500, NB570, and NB573) have been deposited in the Westerdijk Fungal Biodiversity Institute (Utrecht, The Netherlands) and registered as CBS 146568, CBS 146569, CBS 146570, and CBS146571, respectively.

To confirm the identity, seven isolates, i.e., the four isolates from jimson weed and three isolates from tomato, coriander, and parsley (Table 2) were subjected to molecular characterization. Following growth of axenic cultures, mycelium was scraped directly from PSA plates, and 100 $\mu 1$ of lysis buffer (50 mM Tris-HCl pH 7.5, $50 \mathrm{mM}$ EDTA, $3 \%$ sodium dodecyl sulfate, $1 \%$ 2-mercaptoethanol) was added. DNA was isolated according to the method of Goodwin and Lee (1993) and used as a template for PCR. The glyceraldehyde-3-phosphate dehydrogenase ( $g p d)$, RNA polymerase second largest subunit ( $r p b 2)$, and translation elongation factor 1-alpha (tefl) loci were targeted for amplification using primers gpd1/gpd2 (Berbee et al., 1999), RPB2-5F2/fRPB2-7cR (Liu et al., 1999; Sung et al., 2007), and EF1-728F/EF1-986R (Carbone and Kohn, 1999), respectively. Amplification reactions were performed in a $50 \mu \mathrm{l}$ reaction volume containing $75 \mathrm{mM}$ Tris$\mathrm{HCl} \mathrm{pH} \mathrm{9.0,} 20 \mathrm{mM}\left(\mathrm{NH}_{4}\right)_{2} \mathrm{SO}_{4}, 0.01 \%$ (w/v) Tween 20, $1.5 \mathrm{mM} \mathrm{MgCl}_{2}, 200 \mu \mathrm{M}$ each deoxyribonucleotide triphosphate, 1 unit of thermostable DNA polymerase (GoTaq, Promega, Madison, WI, USA) and $400 \mathrm{nM}$ of each relevant oligonucleotide primer. PCR conditions for each gene were according to Woudenberg et al. (2013), and the resulting PCR products were sequenced. Sanger sequencing was performed by GATC Biotech (Konstanz, Germany). Resulting sequences were deposited in GenBank (Table 2). The nucleotide sequences at each of the three targeted loci were identical for the seven selected isolates, and had 100\% identity with corresponding sequences from $A$. crassa type strain CBS 110.38. Corresponding sequence data for $\mathrm{Al}$ ternaria strains representative of 57 species within section Porri and one species within section Euphorbiicola used as outgroup (Woudenberg et al., 2014) were retrieved from GenBank and included in the study. Phylogenetic relation- ships of a combined dataset were estimated by a maximum likelihood analysis with 500 bootstrap replicates using the PhyML program using the Phylogeny.fr web service (Dereeper et al., 2008). This analysis showed that the seven isolates clustered with $A$. crassa reference strains (CBS 103.18, CBS 110.38, CBS 116647, and CBS 116648) confirming their identity (Fig. 2).

Pathogenicity tests were done to complete Koch's pos-

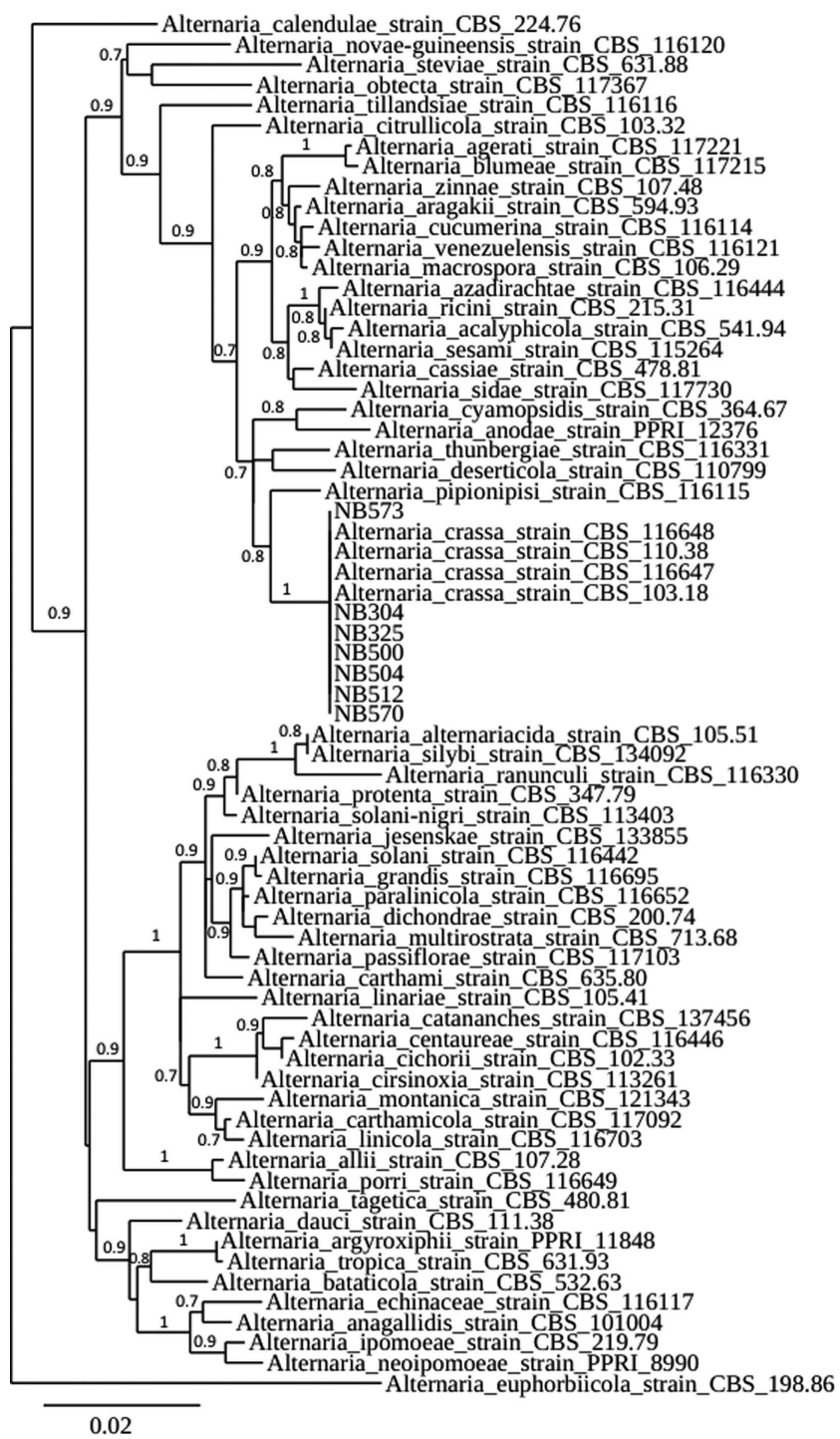

Fig. 2. Phylogenetic tree reconstructed by the maximum likelihood method from the alignment of concatenated sequences of portions of the $g p d, r p b 2$, and tef1 genes from 7 large-spored Alternaria isolates and 62 Alternaria strains representative of 58 species of section Porri and one strain of section Euphorbiicola to root the tree. Sequences were retrieved from GenBank accessions reported in Woudenberg et al. (2014). Bootstrap support values greater than 0.7 are indicated near nodes. The scale bar indicates the expected number of substitution per position. 


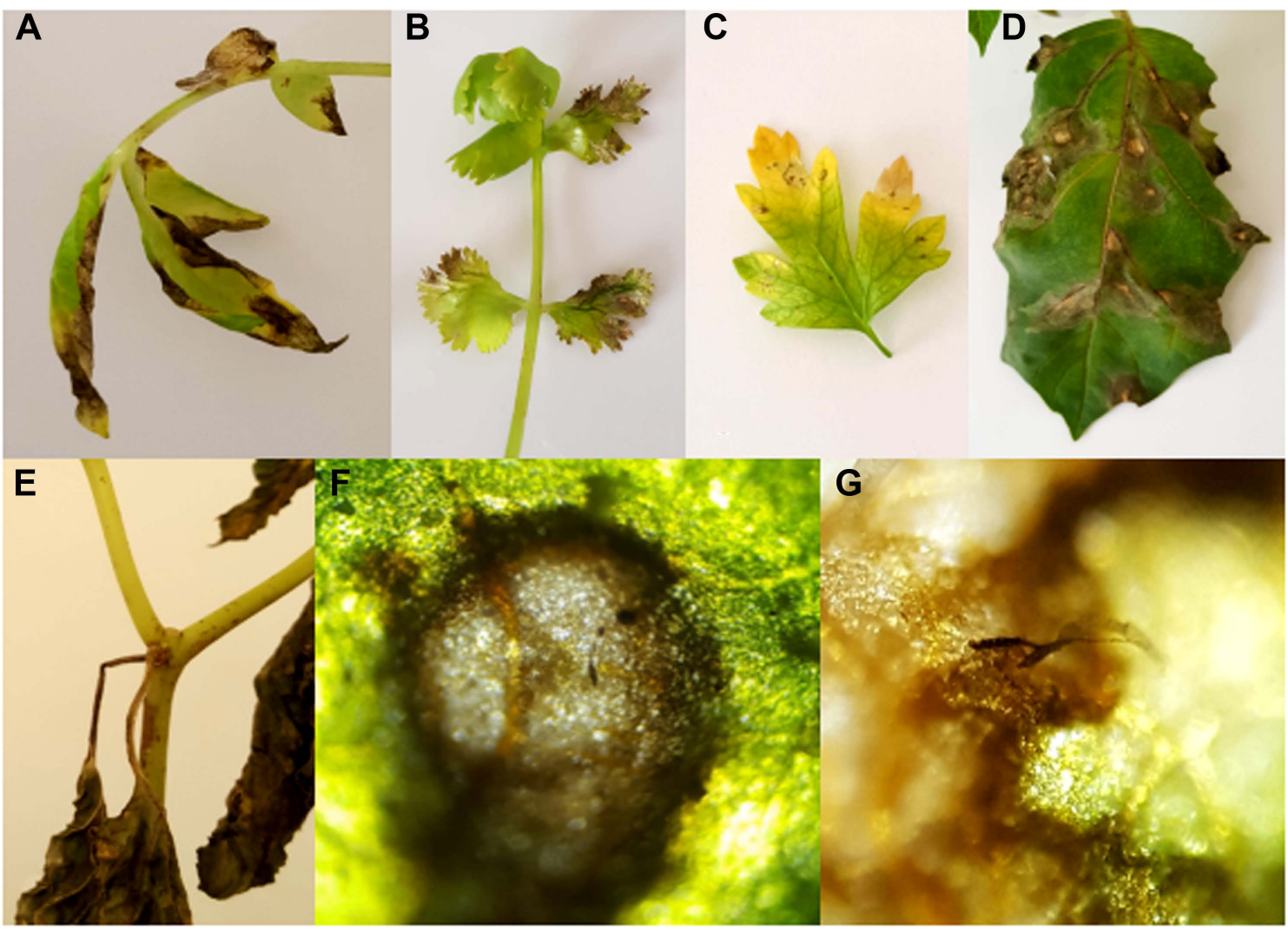

Fig. 3. Leaf spot caused by Alternaria crassa NB573 isolate on inoculated plants: a. tomato (A), coriander (B), parsley (C), jimson weed (D), and symptoms on jimson weed petioles and stem (E). (F, G) Conidia formed on leaf necrosis viewed with a microscope at $40 \times$ and $100 \times$, respectively.

tulates using Datura stramonium, tomato var. Saint Pierre, coriander, and parsley. Before inoculations, plants were grown in a greenhouse under ambient lighting in pots containing sterilized soil ( $3 / 4$ potting soil and $1 / 4$ sand). For inoculum production, 7- to 14-day-old PCA cultures of the nine $A$. crass $a$ isolates were flooded by $10 \mathrm{ml}$ sterilized distilled water supplemented with $0.01 \%$ Tween 80 . Conidia were harvested by scraping the colony surface with a sterilized rubber spatula. The resulting suspension was filtered through a muslin cloth to remove mycelium, and the spore concentration was adjusted to $10^{3}$ spores $/ \mathrm{ml}$ with the help of a hemocytometer. Inoculation experiments were conducted by spraying $10 \mathrm{ml}$ of spore suspension on 2-monthold plants. Three replicates were performed for each test and control plants were sprayed with sterile distilled water. The plants were covered with plastic bags for $48 \mathrm{~h}$ to maintain high relative humidity. Symptom development was monitored for 3 weeks to record the disease progress and the percentage of leaf necrotic area (1.n.a.). Disease severity was rated at 21 days after inoculation (d.a.i.) by visual assessment. Blighted spots with a yellow halo developed on jimson weed, coriander, and tomato leaves 7 d.a.i.
Symptoms were similar to those observed on naturally infected plants (Fig. 3). Necrotic lesions also developed on leaves tips and along petiole margins. For each host plant tested, all isolates had similar aggressiveness except on tomato where isolate NB325 from jimson weed was moderately pathogenic, causing necrotic lesions on about 35 $40 \%$ of leaf area at 21 d.a.i. (Fig. 4). Other isolates were weakly pathogenic on tomato, confirming previous report (Nishikawa and Nakashima, 2013). All A. crassa isolates were moderately pathogenic on coriander (mean 1.n.a., 39.9 $\pm 9.1 \%$ at 21 d.a.i.). Conversely, low infection rate (mean 1.n.a., $10.0 \pm 5.9 \%$ ) was recorded on parsley. Jimson weed plants were significantly the most susceptible host for all tested isolates (Fig. 4). Complete defoliation was observed at 7 d.a.i. with isolates from parsley (NB573), coriander (NB570) and jimson weed (NB705). At 21 d.a.i., A. crassa conidia were regularly formed on jimson weed foliar lesions (Fig. 3F and G), occasionally observed on coriander leaves while no sporulation was observed on inoculated tomato and parsley plants. Control plants did not exhibit any symptom. The fungus was re-isolated from $80 \%$ infected leaves on PCA plates. 

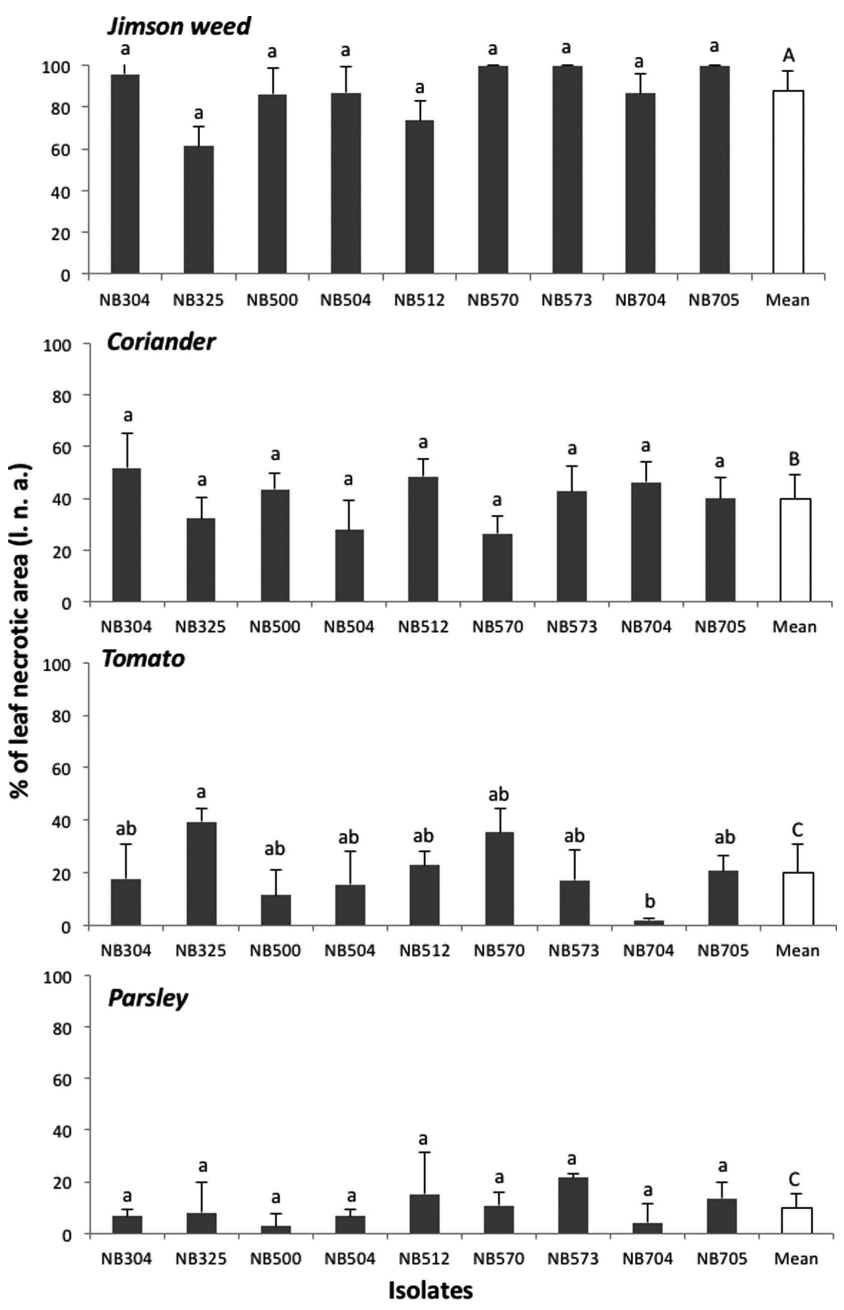

Fig. 4. Virulence of Alternaria crassa isolates on jimson weed, coriander, tomato, and parsley plants under controlled conditions 21 days after inoculation. Multiple-means comparisons were supported by Kruskal-Wallis test. The same letter above bars indicates that means values are not different $(P>0.05)$. Standard letters: statistical analysis within groups; capital letters: statistical analysis between groups.

These results showed that pathogenicity of $A$. crassa isolates obtained from naturally infected plants was not restricted to their original host and may also include other plant species at least under artificial inoculation conditions. According to Woudenberg et al. (2014), the host range of $A$. crassa includes different Solanaceae (Capsicum annuum, Datura stramonium, and Nicandra physalodes). An earlier study reported A. crassa as seed-borne fungus for Datura species (Halfon-Meiri, 1973). This species was also recorded from fennel (Dwivedi et al., 2008) and cereals (Rathod and Chavan, 2010). This species has also been reported in France on Solanum melongena (Messiaen et al., 1991) and its pathogenicity was later confirmed on this host (Stewart-
Wade et al., 1998). The fact that $A$. crassa caused symptoms on tomato plants confirmed previous reports (Boyette, 1986; Stewart-Wade et al., 1998) but the absence of sporulation, already pointed out by Nishikawa and Nakashima (2013) suggests that this fungus is only weakly pathogenic for this plant species.

Due to the data arising from our study, we suggest that A. crassa that has been considered as a potential biological herbicide (Boyette, 1986) might be capable of causing leaf spot disease on members of cultivated plants under certain environmental conditions. The environment of $A$. crassa is determined largely by its original host $D$. stramonium. Variation in host abundance and spatial distribution affects the balance between selection within hosts and gene flow between hosts, and this should determine the evolution of its host-range and adaptation. A. crassa has been reported worldwide including Asia, Europe, Latin and North America, Oceania and also in several African countries except those encompassing the northern part of the continent (Nishikawa and Nakashima, 2020). Besides large-spored species which had been previously described on Solanaceae (Bessadat et al., 2016, 2017, 2019b) and Apiaceae (Bessadat et al., 2019b), we report here the identification of $A$. crassa as a new member of the Algerian mycoflora and as a new potential pathogen for coriander and parsley.

\section{References}

Berbee, M. L., Pirseyedi, M. and Hubbard, S. 1999. Cochliobolus phylogenetics and the origin of known, highly virulent pathogens, inferred from ITS and glyceraldehyde-3-phosphate dehydrogenase gene sequences. Mycologia 91:964-977.

Bessadat, N., Berruyer, R., Hamon, B., Bataille-Simoneau, N., Benichou, S., Kihal, M., Henni, D. E. and Simoneau, P. 2017. Alternaria species associated with early blight epidemics on tomato and other Solanaceae crops in northwestern Algeria. Eur. J. Plant Pathol. 148:181-197.

Bessadat, N., Hamon, B., Bataillé-Simoneau, N., Mabrouk, K. and Simoneau, P. 2019a. Alternaria foliar diseases of solanaceous crops in Algeria: a multi-species threat? Acta Hortic. 1257:63-72.

Bessadat, N., Hamon, B., Bataillé-Simoneau, N., Mabrouk, K. and Simoneau, P. 2019b. First report of Alternaria dauci causing leaf blight of coriander (Coriandrum sativum) in Algeria. Plant Dis. 103:2471.

Bessadat, N., Hamon, B., Henni, D. E. and Simoneau, P. 2016. First report of tomato early blight caused by Alternaria grandis in Algeria. Plant Dis. 100:533.

Boyette, C. D. 1986. Evaluation of Alternaria crassa for biological control of Jimsonweed: host range and virulence. Plant Sci. 45:223-228.

Carbone, I. and Kohn, L. M. 1999. A method for designing 
primer sets for speciation studies in filamentous ascomycetes. Mycologia 91:553-556.

Chan, K. 2002. Jimson weed poisoning: a case report. Perm. J. 6:28-30.

Dereeper, A., Guignon, V., Blanc, G., Audic, S., Buffet, S., Chevenet, F., Dufayard, J.-F., Guindon, S., Lefort, V., Lescot, M., Claverie, J.-M. and Gasquel, O. 2008. Phylogeny.fr: robust phylogenetic analysis for the non-specialist. Nucleic Acids Res. 36:W465-W469.

Dwivedi, M., Agrawal, K. and Agrawal, M. 2008. Fungi associated with fennel seed grown in Rajasthan and their phytopathological effects. J. Phytol. Res. 21:95-100.

Ellis, M. B. and Holliday, P. 1970. Alternaria crassa. IMI descriptions of fungi and bacteria. No. 25. CAB International, Wallingford, UK. pp. 241-250.

Goodwin, D. C. and Lee, S. B. 1993. Microwave miniprep of total genomic DNA from fungi, plants, protists and animals for PCR. BioTechniques 15:438-444.

Halfon-Meiri, A. 1973. Alternaria crassa, a seedborne fungus of Datura. Plant Dis. Rep. 57:960-963.

Hoagland, R. E. and Boyette, C. D. 1994. Pathogenic interactions of Alternaria crassa and phenolic metabolism in Jimsonweed (Datura Stramonium L.) varieties. Weed Sci. 42:44-49.

Holm, L., Doll, J., Holm, E., Pancho, J. V. and Herberger, J. P. 1997. World weeds: natural histories and distribution. John Wiley \& Sons Inc., New York, NY, USA. 1129 pp.

Liu, Y. J., Whelen, S. and Hall, B. D. 1999. Phylogenetic relationships among ascomycetes: evidence from an RNA polymerase II subunit. Mol. Biol. Evol. 16:1799-1808.

Messiaen, C. M., Blancard, D., Rouxel, F. and Lafon, R. 1991. Les maladies des plantes maraichères [Diseases of vegetable crops]. 3rd ed. INRA, Paris, France. 552 pp.

Monaco, T. J., Grayson, A. S. and Sanders, D. C. 1981. Influence of four weed species on the growth, yield, and quality of direct-seeded tomatoes (Lycopersicon esculentum). Weed Sci. 29:394-397.

Nishikawa, J. and Nakashima, C. 2013. Taxonomic characterization and experimental host ranges of four newly recorded species of Alternaria from Japan. J. Phytopathol. 161:604616.

Nishikawa, J. and Nakashima, C. 2020. Japanese species of Alternaria and their species boundaries based on host range. Fungal Syst. Evol. 5:197-281.

Rands, R. D. 1917. Alternaria on Datura and potato. Phytopathology 7:337.

Rathod, S. R. and Chavan, A. M. 2010. Incidence of Alternaria species on different cereals, pulses and oil seeds. J. Ecobiotechnol. 2:63-65.

Simmons, E. G. 2007. Alternaria: an identification manual. CBS biodiversity series 6. CBS Fungal Biodiversity Centre, Utrecht, The Netherlands. 775 pp.

Song, Z. Q. 1987. Studies on the occurrence and control of green bug in Algeria. J. Shenyang Agric. Univ. 18:27-33.

Stewart-Wade, S. M., Lawrie, A. C. and Bmese, E. 1998. An Australian isolate of Alternaria crassa shows potential as a mycoherbicide to control the weed Datura stramonium. Australas. Plant Pathol. 27:186-197.

Sung, G.-H., Sung, J.-M., Hywel-Jones, N. L. and Spatafora, J. W. 2007. A multi-gene phylogeny of Clavicipitaceae (Ascomycota, Fungi): identification of localized incongruence using a combinational bootstrap approach. Mol. Phylogenet. Evol. 44:1204-1223.

Woudenberg, J. H. C., Groenewald, J. Z., Binder, M. and Crous, P. W. 2013. Alternaria redefined. Stud. Mycol. 75:171-212.

Woudenberg, J. H. C., Truter, M., Groenewald, J. Z. and Crous, P. W. 2014. Large-spored Alternaria pathogens in section Porri disentangled. Stud. Mycol. 79:1-47. 